\title{
Perinatal Bone Turnover in Term Human Neonates and the Influence of Maternal Smoking
}

\author{
WOLFGANG HÖGLER, ANDREA SCHMID, GERTRAUD RABER, ELISABETH SÖLDER, \\ GÜNTHER EIBL, PETER HEINZ-ERIAN, AND KLAUS KAPELARI
}

Departments of Pediatrics and Adolescent Medicine [W.H., A.S., G.R., P.H.-E., K.K.] and Gynaecology and Obstetrics [E.S.], University Hospital Innsbruck; and Institute for Biostatistics and Documentation, University of Innsbruck [G.E.], Innsbruck, Austria

\begin{tabular}{|c|c|}
\hline \multicolumn{2}{|c|}{ ABSTRACT } \\
\hline $\begin{array}{l}\text { Bone turnover in neonates appears independently of the } \\
\text { comparably low maternal bone turnover, but there is only sparse } \\
\text { information on the effect of the in utero environment on fetal } \\
\text { bone turnover. Postnatally, the resuming growth velocity and } \\
\text { alterations in mineral homeostasis affect neonatal bone turnover. } \\
\text { This study evaluated the relationship of bone marker concentra- } \\
\text { tions to maternal and fetal auxological variables as well as } \\
\text { maternal smoking and assessed the short-term change in bone } \\
\text { markers during the first days of life. Serum markers of bone } \\
\text { formation [osteocalcin and bone-specific alkaline phosphatase } \\
\text { (BALP)] and bone resorption (C-terminal telopeptide of type I } \\
\text { collagen) were measured in cord blood and at discharge (median } \\
\text { d 3) in } 69 \text { healthy term neonates. Concentrations of BALP were } \\
\text { significantly lower in neonates of smokers ( } n=16) \text { compared } \\
\text { with nonsmokers ( } n=53) \text { both at birth }(p=0.013) \text { and at } \\
\text { discharge ( } p=0.036) \text {. Both cord osteocalcin and BALP were } \\
\text { negatively related to maternal weight and maternal body mass } \\
\text { index. Maternal smoking and pregnancy weight gain were the } \\
\left.\text { predictors of cord BALP ( } r^{2}=0.24 ; p<0.001\right) \text {, whereas the } \\
\text { mode of delivery best predicted cord C-terminal telopeptide of } \\
\text { type I collagen levels }\left(r^{2}=0.19 ; p<0.001\right) \text {. C-terminal } \\
\text { telopeptide of type I collagen and osteocalcin increased signifi- }\end{array}$ & 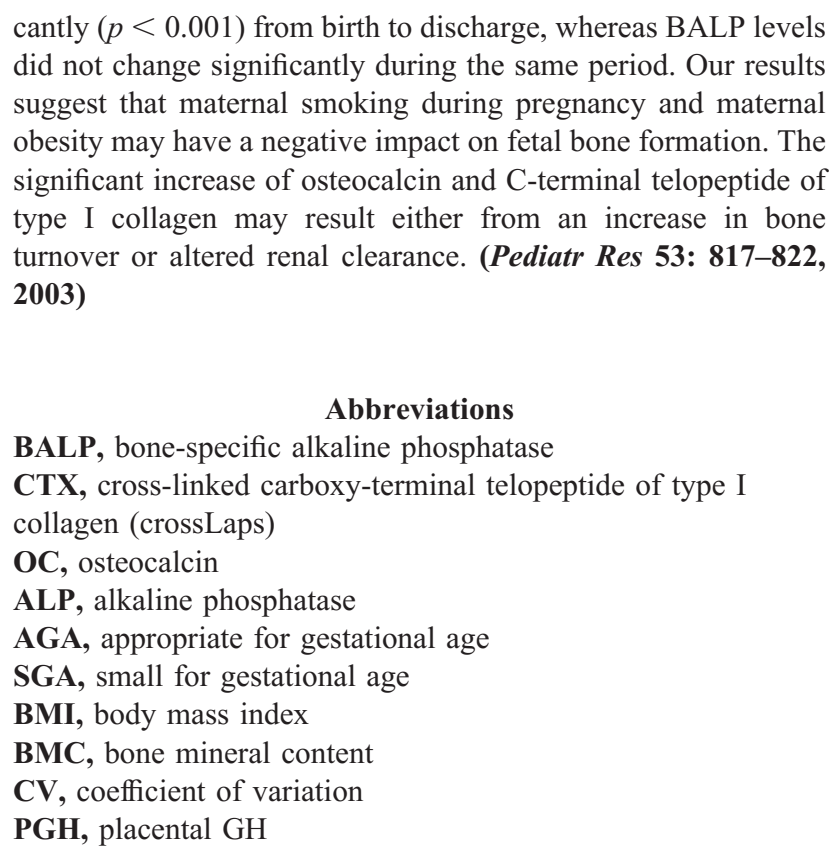 \\
\hline
\end{tabular}

Linear growth in the fetus is high during the second trimester of pregnancy, but drops sharply after the 30th wk of gestation (1). Data obtained from a large cohort of neonates from a Swiss study (2) show that fetal length and weight plateau at approximately $37 \mathrm{wk}$ of gestation, whereas fetal bone mineralization and ossification increase toward the end of pregnancy. This shift from fetal bone growth to maintenance is also evidenced by inverse correlations between gestational age and bone turnover markers in cord blood (3-8) or amniotic fluid (9).

Postnatally, the first 6 to $12 \mathrm{~d}$ represent a transitional growth period. This is characterized by large individual variations (2)

Received November 5, 2001; accepted August 19, 2002.

Correspondence: Wolfgang Högler, M.D., Department of Pediatrics and Adolescent Medicine, University of Innsbruck, Anichstrasse 35, 6020 Innsbruck, Austria; e-mail: wolfgang.hoegler@uibk.ac.at

DOI: 10.1203/01.PDR.0000057984.84206.9E in body weight and hydration state that complicate the assessment of the postnatal growth pattern. Because of the large measurement errors during this period, reliable growth data are sparse and inconsistent for the first days of life. However, along with the postnatal resumption in growth velocity and the concurrent alterations in mineral homeostasis (10), one would expect a parallel increase in bone turnover.

Data on physiologic changes in bone metabolism and growth during the early postnatal period are very sparse. Most studies on this topic were performed in preterm infants, to evaluate osteopenia of prematurity, nutritional status, and growth in different cohorts. All these studies revealed an increase in bone turnover after delivery $(6,8,11-17)$. However, preterm babies miss the phase of peak bone mineral accretion during the last trimester, and postnatal life in these infants is often complicated by serious illness. Thus, their bone turnover is not 
necessarily comparable to term neonates as it is not likely to reflect physiologic conditions.

There is very little information on maternal or fetal factors influencing bone formation and resorption in neonates. The in utero environment may, however, be a particularly critical variable for the growth and bone health of the fetus. A recent study found reduced BMC in neonates of mothers who smoked during pregnancy (18).

The aim of this study was 1) to investigate the relationship between selected bone markers and maternal and fetal auxological and clinical variables, especially maternal smoking, and 2) to assess the postnatal change of these markers during the first days of life in healthy term babies.

\section{METHODS}

\section{Subjects}

All term (37-42 wk of gestation) babies admitted to the neonatal ward during a 2-mo period were eligible to participate in the study. Newborns of mothers known to suffer from any disease likely to affect bone health or calcium metabolism (including hyperparathyroidism, renal failure, chronic diseases requiring corticosteroid treatment, gestational diabetes, thyroid dysfunction) were excluded from the study. Neonates with an abnormal perinatal or postnatal clinical course, e.g. suspected muscular, neurologic, or bone disease, with identifiable genetic syndromes and major congenital malformations were also excluded. All neonates were fed on breast milk, with an energy supplement (Aptamil Primergen; Milupa, Friedrichsdorf, Germany) added if the colostrum supply was inadequate during the early neonatal period. Babies were enrolled in the study only after written informed parental consent was obtained. The study protocol was approved by the local ethics committee.

\section{Design}

Age, weight, and height of the mother at delivery, as well as weight gain during pregnancy, were recorded. The number of cigarettes smoked and the timing of smoking during the pregnancy were documented. Cord blood samples were obtained at the time of birth in all term neonates fulfilling the inclusion criteria of the study. The infants' birth weight was measured with an electronic scale and supine length with a neonatal measuring board. Gestational age and Apgar scores were recorded, as well as placental weight, arterial cord blood $\mathrm{pH}$, and the mode of delivery. Weight of the neonate was measured again at discharge from the hospital.

We analyzed serum markers of bone formation (intact OC and BALP as exclusive markers of osteoblasts) and bone resorption (CTX) in cord blood and on the day of discharge from hospital. Discharge blood samples were taken at routine blood sampling for neonatal screening for inborn errors of metabolism and included the measurement of serum creatinine. Each sample of whole blood $(1 \mathrm{~mL})$ was centrifuged to obtain serum, which was aliquoted and immediately frozen at $-80^{\circ} \mathrm{C}$ within $1 \mathrm{~h}$ after sampling, and stored until the assays were run. This procedure was necessary to avoid the rapid breakdown of the intact OC molecule at room temperature (19). All samples were analyzed in duplicate concurrently.

\section{Assays}

BALP assay. BALP serum levels were measured by a solid-phase, two-site immunoradiometric assay (Tandem-ROstase; Hybritech Inc, San Diego, CA, U.S.A.) based on two MAbs. The intra- and interassay CVs were 6.4 and $4.6 \%$, respectively.

OC assay. Intact $\mathrm{OC}$ was measured by a two-site immunoradiometric assay (Active Human Osteocalcin IRMA; Diagnostic Systems Laboratories, Sinsheim, Germany). Intra- and interassay CVs were 4.6 and $6.0 \%$, respectively.

CTX assay. CTX was measured by ELISA (CrossLaps One Step ELISA; Osteometer Biotech, Herlev, Denmark). This assay uses a polyclonal antiserum raised against an immobilized synthetic peptide with an amino acid sequence (EKAHDGGR) specific for part of the carboxy-terminal telopeptide of the $\alpha_{1}$ (I) collagen chain (20). Intra- and interassay CVs were 5.4 and $7.1 \%$, respectively.

\section{Further Validation}

Kit controls, serum from a cord blood pool $(n=5)$ and a newborn blood pool $(n=5)$ were tested for accuracy. Mean \pm SD recovery rates for BALP in four different concentrations were $98.2 \pm 3.1 \%, 101.5 \pm 7.6 \%$, and $97.2 \pm 8.1 \%$ for kit controls, cord pool, and newborn pool, respectively. The corresponding figures for CTX were $97.2 \pm 3.0 \%, 90.6 \pm 9.7 \%$, and $86.4 \pm 12.6 \%$ and for OC $99.9 \pm 3.7 \%, 96.9 \pm 4.0 \%$, and $96.5 \pm 6.8 \%$. After addition of different amounts of bone marker to the serum pools, the mean \pm SD recovery rates for BALP were $100.2 \pm 6.1 \%$ for the cord pool and $103.4 \pm 8.8 \%$ for the newborn pool. The corresponding figures were $94.1 \pm$ $8.1 \%$ and $95.4 \pm 6.9 \%$ for CTX, and $101.2 \pm 8.2 \%$ and 92.4 $\pm 6.0 \%$ for OC.

\section{Data Analysis}

Wilcoxon's rank test was performed to compare cord blood concentrations with venous concentrations at discharge. The Mann-Whitney $U$ test was used to test for differences in quantitative measurements between groups for sex, maternal smoking, mode of delivery, and weight for gestational age. To investigate the influence that maternal age, maternal and neonatal anthropometric measures, placental weight, gestational age, and renal function had on each measure of bone turnover, we performed univariate and multivariate linear regression analyses on pooled data for cord blood and discharge samples, respectively. Dependent variables were tested for their fit to a normal distribution. Cord CTX and OC at both times were log-transformed before regression analysis. Data are expressed as median (range). Changes at $p<0.05$ were considered significant. Statistical analysis was performed using Statistical Package for Social Sciences (SPSS Inc, Chicago, IL, U.S.A.). 


\section{RESULTS}

Sixty-nine neonates (38 boys, 31 girls) fulfilled inclusion criteria for the study. Their characteristics, and differences between those born by vaginal delivery $(n=47)$ or cesarean section $(n=22)$, are shown in Table 1 . Fifty-four babies were AGA, birth weight between the 10th and 90th percentile for gestational age), 11 were SGA, and four were large for gestational age. The median gestational age at birth was $39.4 \mathrm{wk}$ (range, 37.0 to $41.9 \mathrm{wk}$ ). All infants adapted well to extrauterine life conditions with no signs of respiratory distress, lethargy, irritability, or poor feeding. One-minute Apgar scores were between 6 and 10 for AGA infants and between 5 and 9 for SGA infants. The median duration between cord blood and discharge sampling was $3 \mathrm{~d}$ (range, 1-7 d). Sixty-three of 69 samples $(91.3 \%)$ were drawn between d 2 and 4 . To facilitate interpretation of data with regard to variables that change with increasing postnatal age, we excluded the six discharge samples not drawn on these days from comparisons of cord and discharge bloods.

There was a significant increase in serum CTX levels (7.65 $\mathrm{nM}$; range, 4.28 to $16.43 \mathrm{nM}$ versus $10.22 \mathrm{nM}$; range, 5.38 to $16.45 \mathrm{nM}$, cord versus discharge sample; $p<0.001)$ and OC levels $(16.4 \mathrm{ng} / \mathrm{mL}$; range, 2.6 to $113.1 \mathrm{ng} / \mathrm{mL}$ versus 28.4 $\mathrm{ng} / \mathrm{mL}$; range, 2.5 to $169.5 \mathrm{ng} / \mathrm{mL}$, cord versus discharge sample; $p<0.001$ ). In contrast, serum BALP levels did not change significantly during the same period (Fig. 1).

Neonates born by cesarean section, all of which were elective or after an uncomplicated pregnancy, did not differ in anthropometric variables from infants delivered via the vaginal route. However, they had significantly $(p<0.001)$ higher CTX levels at birth than neonates born by vaginal delivery. Serum CTX levels negatively correlated with gestational age $(r=$ $-0.27 ; p=0.027)$. In multivariate regression analysis, however, the mode of delivery gave the best prediction $\left(r^{2}=0.19\right.$; $p<0.001$ ) of serum CTX levels at birth. Cord OC was related only to maternal weight $(r=-0.28 ; p=0.035$; Fig. $2 A)$; its negative relation to maternal $\mathrm{BMI}$ was close to statistical significance $(r=-0.26 ; p=0.055)$.

To detect possible alterations in neonatal bone turnover as a result of maternal smoking, we compared mothers who smoked throughout pregnancy with nonsmokers. Mothers who stopped smoking within the first trimester of pregnancy were consid-

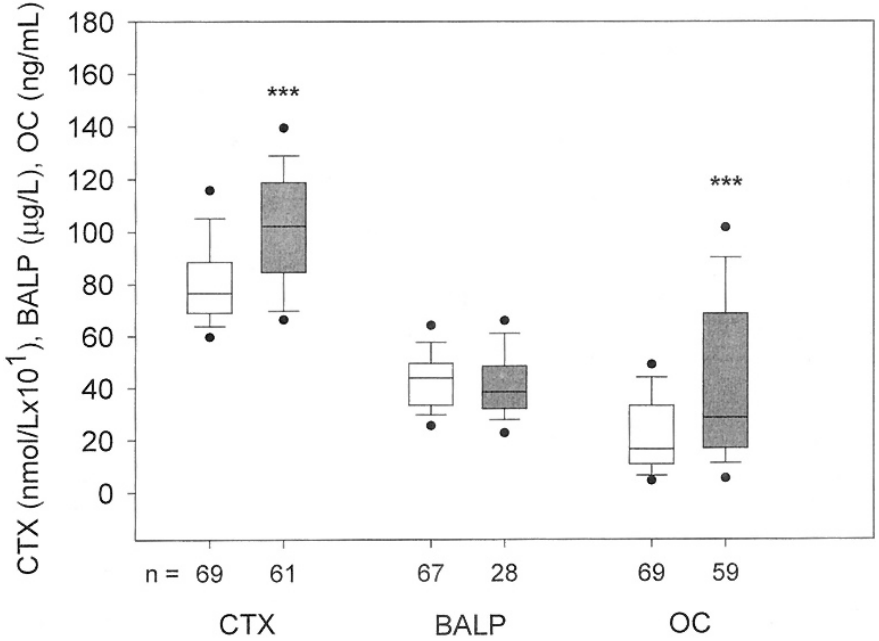

Figure 1. Concentrations of bone turnover markers in cord blood (white boxes) and in peripheral venous blood (shaded boxes) drawn at discharge (postnatal d 2-4). Box plots show median, interquartile values, and 5 th and 95th percentiles. $* * * p<0.001$.

ered nonsmokers. The smoking group consumed a mean of 10.96 cigarettes/d throughout pregnancy. There were no significant differences between neonates of smoking and nonsmoking mothers in anthropometric variables (Table 2). Serum BALP concentrations were significantly reduced in neonates of smokers $(n=16)$ compared with nonsmokers $(n=53)$, both in cord blood ( $p=0.013)$ and at discharge ( $p=0.036$; Fig. 3). In addition, linear regression analysis revealed significant inverse correlations between cord BALP level and maternal weight gain during pregnancy $(r=-0.42 ; p<0.001)$, and maternal weight $(r=-0.35 ; p=0.008)$ and height $(r=$ $-0.28 ; p=0.03)$ at delivery. The negative relation of cord BALP to maternal BMI did not reach statistical significance ( $r$ $=-0.26 ; p=0.057)$. Figure 2 shows the relationship of both bone formation markers with maternal anthropometric variables. When multivariate regression analysis was performed, maternal smoking and pregnancy weight gain were the best predictors of BALP level at birth $\left(r^{2}=0.24 ; p<0.001\right)$. Because of the small number of smokers, we were not able to calculate dose-related consequences of maternal smoking.

Sex, 1-min Apgar score, neonatal anthropometric variables, neonatal weight gain, arterial cord blood $\mathrm{pH}$, serum creatinine,

Table 1. Characteristics of the study population*

\begin{tabular}{|c|c|c|c|}
\hline & $\begin{array}{c}\text { Vaginal delivery } \\
n=47\end{array}$ & $\begin{array}{c}\text { Cesarean section } \\
n=22\end{array}$ & $\begin{array}{c}\text { Total } \\
n=69\end{array}$ \\
\hline SGA/AGA/LGA & $9 / 34 / 4$ & $2 / 20 / 0$ & $11 / 54 / 4$ \\
\hline Gestational age (wk) & $40.2(37.0-41.9)$ & $38.3(37.1-40.3) \dagger$ & $39.4(37.0-41.9)$ \\
\hline Male/female & $28 / 19$ & $10 / 12$ & $38 / 31$ \\
\hline Birth weight (g) & $3250(2430-4300)$ & $3135(2450-3950)$ & $3230(2430-4300)$ \\
\hline Birth length (cm) & $49(45-54)$ & $49(46-54)$ & $49(45-54)$ \\
\hline Ponderal index $\left(\mathrm{g} / \mathrm{cm}^{3}\right) \times 100$ & $2.7(2.3-3.5)$ & $2.7(2.1-3.2)$ & $2.7(2.1-3.5)$ \\
\hline Mothers (smoking/nonsmoking) & $10 / 37$ & $6 / 16$ & $16 / 53$ \\
\hline 1-min APGAR score & $9(5-10)$ & $9(6-10)$ & $9(5-10)$ \\
\hline Neonatal weight change (g) & $-100(-450$ to +560$)$ & $-105(-190$ to +110$)$ & $-100(-450$ to +560$)$ \\
\hline Mother's age (y) & $29(16-37)$ & $31(21-38)$ & $29(16-38)$ \\
\hline
\end{tabular}

* Values are median (range). Differences between data for vaginal and cesarean delivery are not significant, unless otherwise stated.

$\dagger p<0.001$.

LGA, Large for gestational age. 

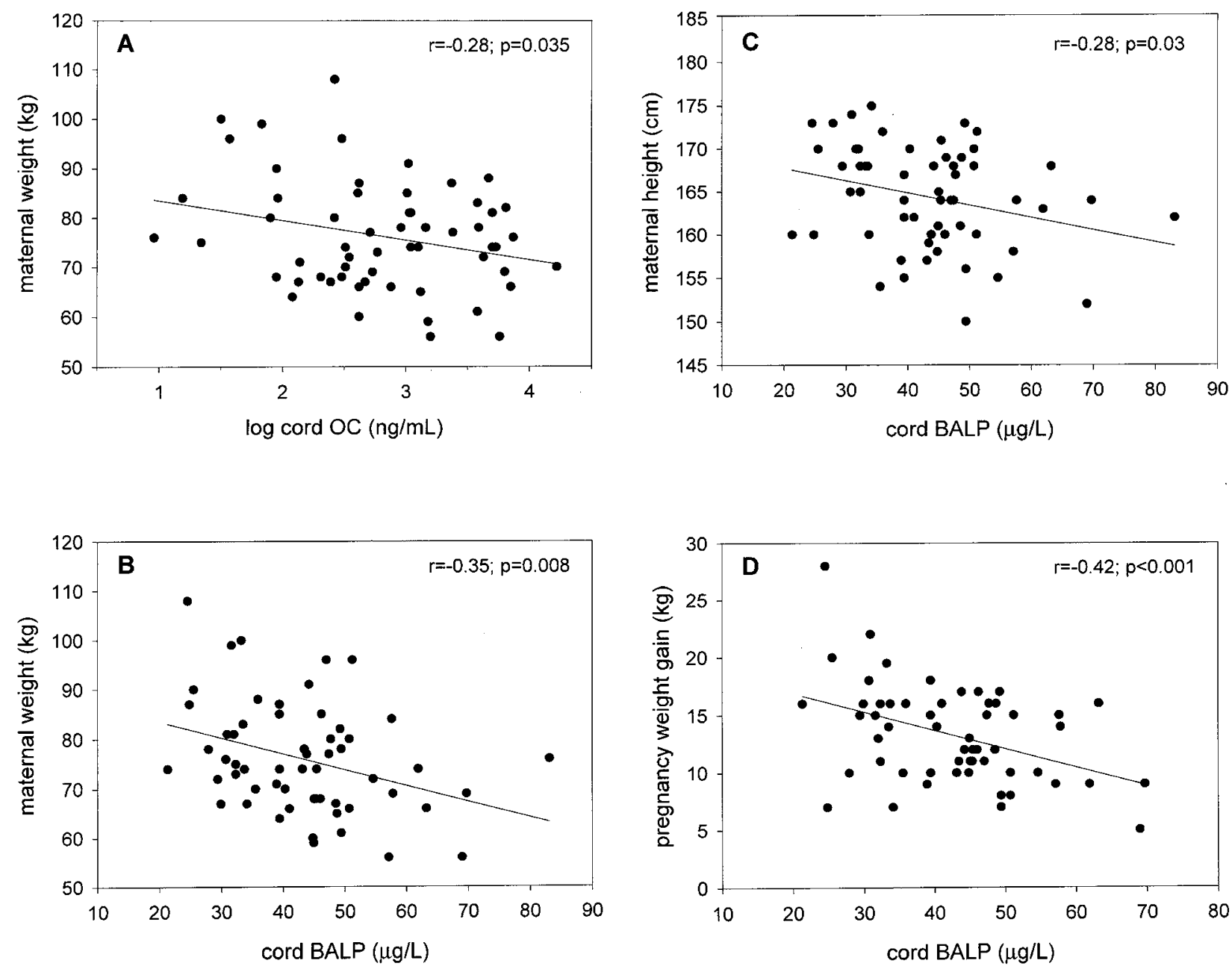

Figure 2. Relationship of cord OC $(A)$ and cord BALP $(B)$ to maternal weight, and cord BALP to maternal height $(C)$ and pregnancy weight gain $(D)$.

Table 2. Characteristics of the study population according to the maternal smoking status*

\begin{tabular}{lcc}
\hline & $\begin{array}{c}\text { Smokers } \\
(n=16)\end{array}$ & $\begin{array}{c}\text { Nonsmokers } \\
(n=53)\end{array}$ \\
\hline Maternal weight $(\mathrm{kg})$ & $79(60-108)$ & $74(56-100)$ \\
Placental weight $(\mathrm{g})$ & $420(400-660)$ & $500(350-790)$ \\
Birth weight $(\mathrm{g})$ & $3220(2630-3950)$ & $3250(2430-4300)$ \\
$\begin{array}{l}\text { Ponderal index } \\
\quad\left(\mathrm{g} / \mathrm{cm}^{3}\right) \times 100\end{array}$ & $2.6(2.1-3.3)$ & $2.7(2.2-3.5)$ \\
Neonatal weight & $-60(-450$ to +110$)$ & $-110(-360$ to +560$)$ \\
$\quad$ change $(\mathrm{g})$ & & \\
Creatinine $(\mu \mathrm{M})$ & $47.74(34.48-70.72)$ & $53.04(20.33-102.54)$ \\
\hline
\end{tabular}

* Values are median (range).

and placental weight were not related to bone marker concentrations. There were no significant differences between SGA, AGA, and large for gestational age babies in any measured variable except birth weight.

\section{DISCUSSION}

This study has discovered effects of the in utero environment on bone modeling of the fetus. Although fetal bone turnover at late gestation appears to be independent of the comparably low maternal turnover $(4,21-23)$, its relationship to maternal factors including anthropometric variables or smoking has not been examined so far using validated methodology. In our study, cord values of BALP and OC were significantly negatively correlated with maternal weight. Cord BALP levels were also inversely correlated with pregnancy weight gain and maternal height. The negative relation of both bone formation markers (BALP and OC) to maternal BMI did not reach statistical significance $(r=-0.26 ; p=0.057$ and $r=-0.26$; $p=0.055$, respectively).

Whether maternal obesity or excessive weight gain during pregnancy could result in alterations in fetal mineral supply during pregnancy, or whether BALP may be positively correlated with term neonatal BMC, as seen in preterm infants (17), is unknown. Interestingly, maternal leptin, which is closely related to BMI, has been found to be a negative predictor of PGH (24). PGH plays a crucial role in fetal growth by a yet unidentified modulation of placental substrate supply to the fetus. Thus, a leptin-induced decrease in PGH caused by maternal obesity might result in a low neonatal bone mass. Increased mechanical stress at delivery for neonates of obese mothers or a decrease in fetal movements in late gestation would be further speculative explanations for this finding. 


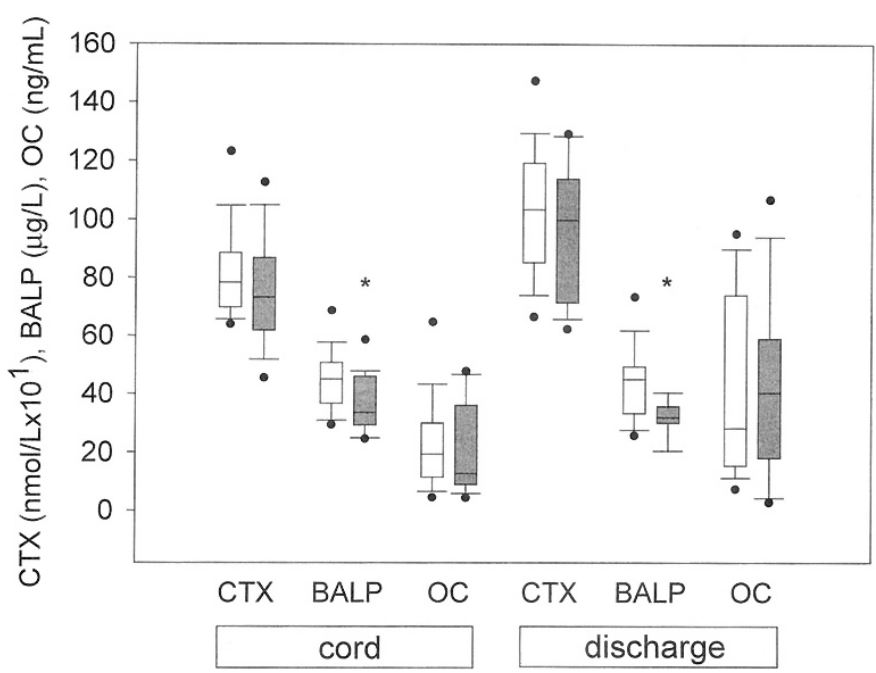

Figure 3. Differences in bone turnover markers between neonates of nonsmokers (white boxes) and smokers (shaded boxes). Box plots show median, interquartile values, and 5 th and 95 th percentiles. The corresponding $p$ values for cord and discharge bloods are $p=0.23$ and $p=0.7$ for CTX, $p=0.04$ and $p=0.01$ for BALP, and $p=0.52$ and $p=0.77$ for $\mathrm{OC}$, respectively. ${ }^{*} p<$ 0.05 .

Further studies on larger cohorts are required to investigate whether maternal obesity could suppress fetal bone formation.

Smoking has deleterious effects on bone in adults of all ages (25-27). However, data on the influence of maternal smoking during pregnancy on bone metabolism in the newborn are very sparse. Jones et al. (28) have shown a negative long-term effect of maternal smoking during pregnancy on both growth and bone mass in a large cohort of prepubertal children born at term. However, studies examining potential early effects of maternal smoking on newborn BMC are inconclusive $(18,29)$, especially as differences between groups according to maternal smoking become insignificant after adjusting BMC for infant length (18). Maternal cigarette smoking is well known to retard fetal growth in a dose-dependent relationship on all anthropometric characteristics of the newborn $(30,31)$. The way in which smoking exerts its negative influence on fetal growth is still not fully understood. Reduced maternal energy intake (32, $33)$, fetal metabolic alterations $(34,35)$ an altered IGF system $(24,36,37)$, and impaired placental function $(38,39)$ have been implicated. We detected significantly reduced concentrations of BALP in infants of smoking mothers, which may reflect impaired bone turnover in these newborns. Interestingly, there was no significant difference between the groups in anthropometric variables (Table 2). Thus, the negative impact of maternal smoking on neonatal bone turnover in our cohort appears to be independent of its well-known effect on fetal growth seen in larger cohorts.

Reduced levels of total ALP have previously been found in neonates of chronic smokers $(34,40)$. This has been attributed to fetal zinc deficiency as a result of placental zinc-trapping, as ALP is a zinc-dependent enzyme (40), and to impaired placental enzymatic activity (34). BALP, however, is the predominant isoenzyme of ALP in healthy term infants (41). It is not a placental enzyme, but an exclusive product of the osteoblast.
Nevertheless, other significant alterations in placental function secondary to maternal smoking (34) may impact on neonatal bone metabolism.

Our results show a significant increase in OC and CTX in term human neonates during the first days of life. There are several potential interpretations of this finding. First, this may be a result of increased bone modeling after the intrauterine deceleration in growth rate and bone turnover during the last weeks of gestation. The increase in these markers is also consistent with the postnatal profile of IGF-1 levels, which increase steadily from the first day of life in term neonates (42-44). A precipitous drop immediately after delivery (cord serum versus d 1) reported in IGF-1 (42) and the osteoblast marker OC (45) has been attributed to the influence of the stress at labor (42). In our study, CTX levels were significantly reduced in neonates born by vaginal delivery. There are, however, no studies investigating the underlying mechanisms by which labor could modulate these effects. A second potential explanation for the increase in CTX and OC would be that the adaptation of the newborn to extrauterine life conditions (e.g. increased muscle activity, oral nutrition) induces significant modulations in bone remodeling in addition to the known alterations in postnatal calcium homeostasis. Calcium levels drop rapidly after cessation of the physiologic fetal hypercalcemia. Subsequently, levels of PTH and 1,25-dihydroxy vitamin D increase during the first week postnatally (10). We speculate that these changes may have induced increased bone remodeling activity in our cohort. Finally, the postnatal increase in CTX and OC may also result from altered renal clearance of these small molecules. However, serum creatinine was not related to any bone marker in linear regression analysis and was measured solely at discharge.

The discrepancy in postnatal change between the two measures of bone formation (BALP and OC) in this study may derive from the different functions of these proteins, which are still not fully understood (46). Alternatively, there may be differences in the timing of their release from bone tissue during the formation process.

\section{CONCLUSIONS}

We conclude from this study that the in utero environment affects bone modeling of the fetus. The markers of bone formation in our study were negatively related to maternal anthropometric measurements, and all markers were unrelated to neonatal measurements. In term babies, there is a significant increase in CTX and OC during the first days of neonatal life, but it remains to be clarified whether this is a result of increased bone modeling, remodeling, or altered renal clearance. BALP appears to be a sensitive tool for the detection of the effects of maternal smoking on bone. Certainly our results suggest that maternal smoking during pregnancy has a negative impact on fetal and neonatal bone turnover. Furthermore, these markers may provide information about whole body turnover of bone and collagen that is complementary to accepted clinical measures of growth and bone mineralization (17), especially in neonates, in whom traditional methods are less applicable. Further studies are required to further explore the relationship 
between maternal obesity, maternal smoking, labor, and neonatal bone turnover.

Acknowledgments. The authors thank Gabriele Staudacher and Mariana Ciachi for excellent technical assistance, and the nursing staff of Innsbruck University Labor and Delivery Suite, also Dr. Erika Pastner for obtaining fetal cord and neonatal serum samples. We also acknowledge the invaluable contribution of Dr. Helen Woodhead and Dr. Joern-Oliver Sass in discussing and reviewing the manuscript.

\section{REFERENCES}

1. Tanner JM 1989 Growth before birth. In: Tanner JM (ed) Foetus into Man. Physical Growth from Conception to Maturity. Castlemead, London, pp 36-50

2. Largo RH, Wälli R, Duc G, Fanconi A, Prader A 1980 Evaluation of perinatal growth. Helv Paediat Acta 35:419-436

3. Kajantie E, Hytinantti T, Koistinen R, Risteli J, Rutanen EM, Seppala M, Andersson S 2001 Markers of type I and type III collagen turnover, insulin-like growth factors, and their binding proteins in cord plasma of small premature infants: relationships with fetal growth, gestational age, preeclampsia, and antenatal glucocorticoid treatment. Pediatr Res 49:481-489

4. Ogueh O, Khastgir G, Studd J, Jones J, Alaghband-Zadeh J, Johnson MR 1998 The relationship of fetal serum markers of bone metabolism to gestational age. Early Hum Dev 51:109-112

5. Hytinantti T, Rutanen EM, Turpeinen M, Sorva R, Andersson S 2000 Markers of collagen metabolism and insulin-like growth factor binding protein-1 in term infants. Arch Dis Child Fetal Neonatal Ed 83:F17-F20

6. Mora S, Prinster C, Bellini A, Weber G, Proverbio MC, Puzzovio M, Bianchi C, Chiumello G 1997 Bone turnover in neonates: changes of urinary excretion rate of collagen type I cross-linked peptides during the first days of life and influence of gestational age. Bone 20:563-566

7. Tsukahara H, Watanabe Y, Hirano S, Tsubokura H, Kimura K, Mayumi M 1999 Assessment of bone turnover in term and preterm newborns at birth: measurement of urinary collagen crosslink excretion. Early Hum Dev 53:185-191

8. Seibold-Weiger K, Wollmann HA, Ranke MB, Speer CP 2000 Plasma concentrations of the carboxyterminal propeptide of type I procollagen (PICP) in preterm neonates from birth to term. Pediatr Res 48:104-108

9. Harrast SD, Kalkwarf HJ 1998 Effects of gestational age, maternal diabetes, and intrauterine growth retardation on markers of fetal bone turnover in amniotic fluid. Calcif Tissue Int 62:205-208

10. Kruse K 1992 [Perinatal calcium metabolism. Physiology and pathophysiology] Monatsschr Kinderheilkd 140:S1-S7

11. Shiff Y, Eliakim A, Shainkin-Kestenbaum R, Arnon S, Lis M, Dolfin T 2001 Measurements of bone turnover markers in premature infants. J Pediatr Endocrinol Metab 14:389-395

12. Naylor KE, Eastell R, Shattuck KE, Alfrey AC, Klein GL 1999 Bone turnover in preterm infants. Pediatr Res 45:363-366

13. Younoszai MK, Haworth JC 1968 Excretion of hydroxyproline in urine by premature and normal full-term infants and those with intrauterine growth retardation during the first three days of life. Pediatr Res 2:17-21

14. Pittard III WB, Geddes KM, Hulsey TC, Hollis BW 1992 Osteocalcin, skeletal alkaline phosphatase, and bone mineral content in very low birth weight infants: a longitudinal assessment. Pediatr Res 31:181-185

15. Delmas PD, Glorieux FH, Delvin EE, Salle BL, Melki I 1987 Perinatal serum bone Gla-protein and vitamin D metabolites in preterm and fullterm neonates. J Clin Endocrinol Metab 65:588-591

16. Bhandari V, Fall P, Raisz L, Rowe J 1999 Potential biochemical growth markers in premature infants. Am J Perinatol 16:339-349

17. Crofton PM, Shrivastava A, Wade JC, Stephen R, Kelnar CJ, Lyon AJ, Mcintosh N 1999 Bone and collagen markers in preterm infants: relationship with growth and bone mineral content over the first 10 weeks of life. Pediatr Res 46:581-587

18. Godfrey K, Walker-Bone K, Robinson S, Taylor P, Shore S, Wheeler T, Cooper C 2001 Neonatal bone mass: influence of parental birthweight, maternal smoking, body composition, and activity during pregnancy. J Bone Miner Res 16:1694-1703

19. Gundberg CM 1998 Biology, physiology, and clinical chemistry of osteocalcin. J Clin Ligand Assay 21:128-138
20. Rosenquist C, Fledelius C, Christgau S, Pedersen BJ, Bonde M, Qvist P, Christiansen C 1998 Serum CrossLaps one step ELISA: first application of monoclonal antibodies for measurement in serum of bone-related degradation products from C-terminal telopeptides of type I collagen. Clin Chem 44:2281-2289

21. Yamaga A, Taga M, Hashimoto S, Ota C 1999 Comparison of bone metabolic markers between maternal and cord blood. Horm Res 51:277-279

22. Yasumizu T, Kato J 1996 Concentrations of serum markers of type I collagen synthesis and degradation and serum osteocalcin in maternal and umbilical circulation. Endocr J 43:191-195

23. Shima M, Seino Y, Tanaka Y, Yabuuchi H, Tsutsumi C, Moriuchi S 1985 Bone $\gamma$-carboxyglutamic acid containing protein in the perinatal period. Acta Paediatr Scand 74:674-677

24. Coutant R, Boux DC, Douay O, Mathieu E, Rouleau S, Beringue F, Gillard P, Limal JM, Descamps P 2001 Relationships between placental GH concentration and maternal smoking, newborn gender, and maternal leptin: possible implications for birth weight. J Clin Endocrinol Metab 86:4854-4859

25. Nguyen TV, Kelly PJ, Sambrook PN, Gilbert C, Pocock NA, Eisman JA 1994 Lifestyle factors and bone density in the elderly: implications for osteoporosis prevention. J Bone Miner Res 9:1339-1346

26. Hopper JL, Seeman E 1994 The bone density of female twins discordant for tobacco use. N Engl J Med 330:387-392

27. Pocock NA, Eisman JA, Kelly PJ, Sambrook PN, Yeates MG 1989 Effects of tobacco use on axial and appendicular bone mineral density. Bone 10:329-331

28. Jones G, Riley M, Dwyer T 1999 Maternal smoking during pregnancy, growth, and bone mass in prepubertal children. J Bone Miner Res 14:146-151

29. Venkataraman PS, Duke JC 1991 Bone mineral content of healthy, full-term neonates: effect of race, gender, and maternal cigarette smoking. Am J Dis Child 145:1310-1312

30. Zaren B, Lindmark G, Gebre-Medhin M 1996 Maternal smoking and body composition of the newborn. Acta Paediatr 85:213-219

31. Cliver SP, Goldenberg RL, Cutter GR, Hoffman HJ, Davis RO, Nelson KG 1995 The effect of cigarette smoking on neonatal anthropometric measurements. Obstet Gynecol 85:625-630

32. Haste FM, Brooke OG, Anderson HR, Bland JM 1991 The effect of nutritional intake on outcome of pregnancy in smokers and non-smokers. Br J Nutr 65:347-354

33. D'Souza SW, Black P, Richards B 1981 Smoking in pregnancy: associations with skinfold thickness, maternal weight gain, and fetal size at birth. BMJ (Clin Res Ed) 282:1661-1663

34. Jauniaux E, Biernaux V, Gerlo E, Gulbis B 2001 Chronic maternal smoking and cord blood amino acid and enzyme levels at term. Obstet Gynecol 97:57-61

35. Langhoff-Roos J, Wibell L, Gebre-Medhin M, Lindmark G 1993 Effect of smoking on maternal glucose metabolism. Gynecol Obstet Invest 36:8-11

36. Heinz-Erian P, Spitzmuller A, Schrocksnadel H, Birnbacher R 1998 Maternal smoking and inhibition of fetal growth factor. [letter] JAMA 279:1954

37. Beratis NG, Varvarigou A, Makri M, Vagenakis AG 1994 Prolactin, growth hormone and insulin-like growth factor-I in newborn children of smoking mothers. Clin Endocrinol (Oxf) 40:179-185

38. Bush PG, Mayhew TM, Abramovich DR, Aggett PJ, Burke MD, Page KR 2000 A quantitative study on the effects of maternal smoking on placental morphology and cadmium concentration. Placenta 21:247-256

39. Sastry BV 1991 Placental toxicology: tobacco smoke, abused drugs, multiple chemical interactions, and placental function. Reprod Fertil Dev 3:355-372

40. Kuhnert BR, Kuhnert PM, Lazebnik N, Erhard P 1988 The effect of maternal smoking on the relationship between maternal and fetal zinc status and infant birth weight. J Am Coll Nutr 7:309-316

41. Crofton PM 1992 Wheat-germ lectin affinity electrophoresis for alkaline phosphatase isoforms in children: age-dependent reference ranges and changes in liver and bone disease. Clin Chem 38:663-670

42. Giudice LC, de Zegher F, Gargosky SE, Dsupin BA, de las Fuentes L, Crystal RA, Hintz RL, Rosenfeld RG 1995 Insulin-like growth factors and their binding proteins in the term and preterm human fetus and neonate with normal and extremes of intrauterine growth. J Clin Endocrinol Metab 80:1548-1555

43. Lineham JD, Smith RM, Dahlenburg GW, King RA, Haslam RR, Stuart MC, Faull L 1986 Circulating insulin-like growth factor I levels in newborn premature and full-term infants followed longitudinally. Early Hum Dev 13:37-46

44. Tato L, Dal Moro A, Piemonte G, Vigi V, Pizzo P, Volpato S, Gaburro D 1981 A longitudinal study on plasma somatomedin activity in full-term, preterm and smallfor-gestational age newborns. Biol Neonate 39:160-164

45. Loughead JL, Mimouni F, Ross R, Tsang RC 1990 Postnatal changes in serum osteocalcin and parathyroid hormone concentrations. J Am Coll Nutr 9:358-362

46. Calvo MS, Eyre DR, Gundberg CM 1996 Molecular basis and clinical application of biological markers of bone turnover. Endocr Rev 17:333-368 